\title{
Supply Chain Finance Credit Risk Evaluation Method Based on Self-Adaption Weight
}

\author{
Yueliang Su, Nan Lu \\ School of Business, South China University of Technology, Guangzhou, China \\ Email: 24848451@qq.com
}

Received 18 June 2015; accepted 12 July 2015; published 17 July 2015

Copyright (C) 2015 by authors and Scientific Research Publishing Inc.

This work is licensed under the Creative Commons Attribution International License (CC BY). http://creativecommons.org/licenses/by/4.0/

c) (i) Open Access

\begin{abstract}
Credit risk is the core issue of supply chain finance. In the supply chain, problems happened in different enterprises can influent the whole to different degrees through transferring, thus statuses of all enterprises and their different influences should be considered when evaluating the supply chain's credit risk. We examine the characters of supply chain network and complex network, use the local growing complex network to simulate the real supply chain, use cluster analysis to classify the company into several levels; Introducing each level's self-adaption weight formula according to the company's quantity and degrees of this level and use the weight to improve the credit evaluation method. The research results indicate that complex network can be used to simulate the supply chain. The credit risk evaluation (CRE) of an enterprise level with bigger note degrees has a greater weight in the supply chain system's CRE, thus has greater effect on the whole chain. Considering different influences of different enterprise levels can improve credit risk evaluation method's sensitivity.
\end{abstract}

Keywords

Supply Chain Finance, Credit Risk, Self-Adaption Weight, Complex Network

\section{Introduction}

Supply chain finance is a financial service that uses controllable credit risk of the whole supply chain, instead of the uncontrollable credit risk of the SME, to solve SME's financing problem. Thus, credit risk is the core issue of supply chain finance and it needs a perfect mechanism to measure the supply chain system's credit risk from a global perspective. Meanwhile, enterprises in the supply chain are divided into core and non-core ones, Lu S.Q. thinks that core enterprise has the supply chain's bottleneck constraint resources, decides the smooth operation and performance of the supply chain, organizes division of labor and coordinates resource allocation, forms and 
enhances the supply chain's core competence [1]. The empirical research also indicates that the supply chain network has heterogeneity. It means that core enterprise has business transactions with lots of other enterprises (from the perspective of topology, core node enterprise has edge connections with lots of other node enterprises), while most enterprises just have one or few partners [2] [3]. So different enterprises in a supply chain have status differences and the core one has a greater influence on the system's credit risk. Therefore, enterprises' status differences should be taken into account when supply chain finance's credit risk is evaluated.

In the past, many scholars had conducted research on single enterprise credit risk [4] [5], but single enterprise credit risk evaluation was unable to meet the requirements of supply chain finance, thus scholars began to study the supply chain system's credit risk from various angles [6]-[10]. These researches use different methods to evaluate supply chain's credit risk, but lack description of supply chain's complexity and dynamic evolution.

There are complex trade relations among different supply chains and different enterprises in a supply chain, and new enterprises constantly replace the old ones during the operation, that is to say, the supply chain network is evolving, thus it is necessary to study supply chain network with complex system theory and method. Choi firstly uses complex adaptive system theory to study supply chain, and points out that there are complex business relations among the node enterprises in a supply chain [11]. Thadakama Uabuild's model specifies new node enterprise's type. Then, it chooses other nodes which have different types based on node degree priority rules [12]. In Thadakama Ua's model, preferential attachment is based on universal search, but in reality, the enterprise selects partners in some other enterprises on the basic of certain preferences [13]. Li X. limits the preferred mechanism of a new node in a local world, but nodes in the local world are randomly chosen [2], which means enterprise's preferences when building a local world are neglected. Gardenes proposes a GM model, gives each new node a positional parameter to measure the geometric distances between the new node and other given nodes and gives the maximum distance, if geometric distance between an old node and the new one is less than the maximum. Then, the old node is selected into the new one's local world [14]. However, just considering the geometric distance cannot fully describe enterprise's preferences about choosing a local world.

Besides, Xia L.M. et al. set "financing entity evaluation, financing debt evaluation and macro environment evaluation" as target layer when they use AHP to measure SME's credit risk on the background of supply chain [15]. The existing methods of supply chain credit risk evaluation usually just consider finance enterprise and its counterparty (usually refers to the core enterprise), but neglect influence from enterprises that have no direct business with finance enterprise and differentiated effects from enterprises' status differences, which results in biased assessment results.

According to the above analysis, this paper studies the supply chain finance's credit risk evaluated problem based on an evolving local-world of complex network and the classification of enterprises' impact. Firstly, it improves the preferred mechanism of enterprises in the supply chain complex network and regards the degree of isomerization between the new enterprise and an old one as the determinant of whether the old one enters the new one's local-world, while regarding the degree of old enterprise node that is in the local-world as the determinant of whether it becomes the new one's partner, to build supply chain complex network; Secondly, it uses the cluster analysis to layer the supply chain network and gives the adaptive weight formula of enterprises in each layer; Then, it uses the weight to improve the existing credit risk evaluation model and finally a numerical example is provided to verify the conclusions.

\section{The Characteristic Factors Analysis of Supply Chain Finance's Credit Risk}

\subsection{The Complex Dynamic Contagion of Risk}

The supply chain has several characteristics: the core enterprise has the supply chain's bottleneck constraint resources, coordinates and controls the development of supply chain, while other enterprises attach themselves to a certain link of the chain to survive; A raw material supplier supplies raw material to multiple manufacturers, a manufacturer purchases materials from multiple suppliers and finished goods are distributed to multiple retailers, also a retailer sells products from different manufacturers. It means that enterprises have differences in qualification, status and function. Meanwhile, the development of an enterprise is closely related to the liquidity, product trading and information interaction with other enterprises. Therefore, supply chain is a complex supplydemand network which is made of several hierarchies and multiple enterprises in each hierarchy.

Due to the closely relation of supply chain network, an enterprise's problem can infect other node enterprises through the edge, until affects the entire network and takes a toll on the whole: If an exception happens in the 
core enterprise, it would seriously influence the supply chain's logistic and cash flow, even threatens the survival of the chain; And if an exception happens in a SME, it would also affect the chain while the destructiveness is lower [16].

The existing methods of supply chain credit risk evaluation usually just consider finance enterprise and its counterparty (usually refers to the core enterprise), but neglect influence from other enterprises [15]. But for enterprises that have no direct business with finance enterprise and have lower status (have business transaction with less enterprises), although there are no direct influence on the finance enterprise when a crisis hits them, the risk can affect the whole chain through the edges, so the finance enterprise also will be affected. Therefore, the risk condition of all enterprises in the supply chain should be taken into account when evaluating the whole supply chain's credit risk to make the assessment more accurate and reasonable.

\subsection{The Differential Impacts on the Whole Supply Chain from the Risk of Each Enterprise}

The credit risk condition of each enterprise differently influences the whole supply chain's credit risk, for example, the impact extent of the core enterprise is bigger than that of an enterprise new to the supply chain. Thus the different impact extents from different enterprises should be considered. Otherwise, the chain's credit risk would be overestimated and increase the difficulty of SMEs finance or would be underestimated and increase the risk of default that the bank takes. This paper gives each level's CRE a weight to embody these diversities, especially, the weight is adaptive so that it can change itself due to the supply chain's dynamic evolution.

\section{Model Description}

\subsection{The Build and Analyze of Supply Chain Complex Network}

In order to examine our model, we use customer data sets of a telecommunication operation to conduct our case study. According to the characteristics of the mobile user, we can grasp a customer's consumption characteristics by analyzing his consumption listing within 3 months. Hence, we select customer consumption listings from November 2014 to January 2015 and churn data for February 2015 as our model data. This data contains a total of 1,048,575 records and 25 customer attributes like customer ID, costs, traffic, voice package information etc.

Both supply chain's members and enterprise's partners are a two-way choice and there are clear preferences. For example, when a new enterprise and an old one are going to establish connections, the new one prefers to choose a stronger old enterprise while the old one also prefers to choose a stronger new enterprise, on balance, new and old enterprises that have similar strength and status become partners. This preference dictates that a new enterprise always chooses its partners in some enterprises that have similar strength and status with it, the enterprise group that compose of these enterprises is the new enterprise's local-world, which show as $\Psi(t)$. Besides, although old enterprises in $\Psi(t)$ share similar strength and status, there still are ranking points among them, and the new enterprise tends to cooperating with the better. Therefore, this section firstly uses the degree of isomerization between enterprises to build $\Psi(t)$, then the new enterprise chooses partners from $\Psi(t)$ according to the degree of node enterprises.

This paper uses enterprise culture, external performance, security and communication ability to measure the degree of isomerization between the new enterprise and an old one. The probability of an old enterprise entering $\Psi(t)$ is increasing with the degree of isomerization, so $\Psi(t)$ is made up of these screened enterprises and the new enterprise preferentially attaches according to old enterprises' node degrees. Thus, a complex network of supply chain is formed. Concrete steps are:

1) Let $N$ denotes the total number of enterprises in the supply chain, when $t=0$, initializing a network with $m_{0}$ enterprises, let enterprises connect with others randomly and each enterprise is randomly distributed a vector: $\left(x_{i}^{1}, x_{i}^{2}, \cdots, x_{i}^{n}\right)$, each $x_{i}^{y}$ denotes an indicator mentioned above.

2) A new node enterprise $v_{j}$ enters the supply chain each unit interval and randomly get a vector $\left(x_{j}^{1}, x_{j}^{2}, \cdots, x_{j}^{n}\right)$, then calculating the degree of isomerization based on the following formula:

$$
Q_{i}=\left(x_{i}^{1}-x_{j}^{1}\right)^{2}+\left(x_{i}^{2}-x_{j}^{2}\right)^{2}+\cdots+\left(x_{j}^{n}-x_{j}^{n}\right)^{2}
$$

Thus, the probability of the old enterprise entering $\Psi(t)$ is: 


$$
q_{i}=\frac{1}{Q_{i}}=\frac{1}{\sqrt{\left(x_{i}^{1}-x_{j}^{1}\right)^{2}+\left(x_{i}^{2}-x_{j}^{2}\right)^{2}+\cdots+\left(x_{j}^{n}-x_{j}^{n}\right)^{2}}},\left(i=1,2, \cdots, m_{0}+t\right)
$$

That means, the degree of isomerization is decreasing with the proximity of a new and an old enterprises' strength and status, and the smaller the degree of isomerization is, the more likely the old enterprise enters $\Psi(t)$.

3) Using roulette wheel, based on Equation (2), selecting $M_{0}+M_{t}$ enterprises from $m_{0}+t$ enterprises to be the amount of enterprises in $\Psi(t) \quad\left(M_{0}+M_{t} \leq m_{0}+t\right) . M_{t}$ denotes the growth rate of $\Psi(t)$ over time.

4) Calculate the connective probability between each old enterprise in $\Psi(t)$ and the new one:

$$
\prod_{v_{l}}\left(v_{l} \rightarrow v_{j}\right)=\frac{d_{v_{l}}}{\sum_{v_{l}^{\prime} \in \Psi(t)} d_{v_{l}^{\prime}}}, v_{l} \in \Psi(t)
$$

Then, let the new enterprise use roulette wheel to establish edge connections with m old enterprises in $\Psi(t)$. And $m$ is the new node's degree, $d_{v}$ is the $v$ node's degree.

5) Repeat the above steps until the amount of enterprises in the supply chain network reaches $N$.

Thus, a supply chain network with self-organization, dynamic, complexity, hierarchical and isomerism is established.

\subsection{The Credit Risk Evaluation of Supply Chain Complex Network}

\subsubsection{The Generation of Adaptive Weights}

Risk is of contagion and diffusibility so that it can transfer to each node through edges of the supply chain network, thus influencing the whole supply chain's risk status. But crises happen to different enterprises cause damages in different degrees, and enterprises that have more trades with others may bring greater influence. Therefore, these differential effects should be distinguished to improve the accuracy of the risk measurement.

Nodes in the complex network have different degrees, and the amounts of partner of enterprises in the supply chain network are differential. Thus layering the supply chain network based on the number of partner can be achieved through layering the complex network based on the node's degree. Then the contribution degree difference to the supply chain credit risk results from enterprises' status difference can be reflected.

Using SPSS methods to cluster enterprise nodes in the supply chain complex network, dividing the network into $\mathrm{E}$ layers based on the difficulty level of risk contagion (the node's degree). In the e layer, the scope of node degree is $\left[\underline{d_{e}}, \overline{d_{e}}\right],(e=E, E-1, \cdots, 1)$, and

$$
\overline{d_{E}} \geq \underline{d_{E}} \geq \overline{d_{E-1}} \geq \underline{d_{E-1}} \geq \cdots \geq \overline{d_{2}} \geq \underline{d_{2}} \geq \overline{d_{1}} \geq \underline{d_{1}}
$$

The model abstracts the supply chain system into an E layer's complex network, and assigns each layer a weight as follow:

$$
\beta_{e}=\frac{\sum_{k=1}^{n_{e}} d_{v_{e k}} \div n_{e}}{\sum_{h=1}^{J}\left(\sum_{k=1}^{n_{h}} d_{v_{h k}} \div n_{h}\right)}
$$

$d_{v_{e k}}$ is the degree of the $k$ th enterprise node's in the eth layer, $n_{e}$ is the amount of enterprise in the eth layer. Thus $\beta_{e}$ can change automatically with the development of enterprises and the evolution of the supply chain, which means the weight is adaptive. $\beta_{e}$ describes the contribution degree to the system's CRE from the CRE of enterprises in the eth layer, and differences among each $\beta$ describe different influences from different enterprise layers.

\subsubsection{The Establishment of the Evolution Model}

In the supply chain, different enterprises have different positions, and different enterprises' problems have dif- 
ferent effects on the supply chain, that means the contribution degree to the system's CRE from different enterprises is different. Therefore, emphasizing the different influences results from enterprises' status difference which can be described by $\beta$ is important when evaluating the supply chain's credit risk.

Assuming that enterprise $g(g=1,2, \cdots, N)$ in the supply chain has a integration of credit state $S I_{g}$, a larger $S I_{g}$ means a better credit state and a smaller credit risk. Setting $g=1,2$ means financing enterprise and its counter party, respectively. $\phi$ means the credit state of enterprise's exterior environment. $\alpha_{1}, \alpha_{2}, \alpha_{3}, \alpha_{4}$ is the weight of credit state of financing enterprise, core enterprise, other enterprises and exterior environment, respectively. Then the overall credit state of the supply chain complex network is:

$$
W S=\alpha_{1} S I_{1}+\alpha_{2} S I_{2}+\alpha_{3} \frac{\sum_{e=1}^{E}\left(\sum_{k=1}^{n_{e}} S I_{e k} \beta_{e}\right)}{N-2}+\alpha_{4} \phi \quad\left(S I_{e k} \neq S I_{1}, S I_{2}\right)
$$

Similarly, a larger WS means a better credit state. This paper defines the overall credit of the supply chain complex network as

$$
R=1 / W S
$$

The larger the WS is, the smaller the $R$ is, which means a better overall credit state and a smaller overall credit risk.

\section{Application}

To verify the fitness of the model and the conclusions above, this paper selects a supply chain with 200 enterprises as case study. In order to fit conveniently, choosing two degree of isomerization (enterprise culture and external performance) as the standard when establishing $\Psi(t)$. The example is no-dimensional to make calculation easy.

\subsection{The Fitting of Complex Network and Supply Chain Network}

Setting $N=200, m_{0}=10, m=4, M_{0}=m_{0}+\frac{t}{10}$, using Matlab to run the model can get results as follow:

Research shows that although the network size of supply chain is very large, its average path length is relatively small and its clustering coefficient is already near zero [17]. The average path length of this network is $L=2.8416$, which is relatively small; The clustering coefficient of this network is $c=0.097227$, which is also near zero.

As Figure 1 shows, most nodes in the network have lower degree, approximately 4, and only a few nodes have higher degree. Secondly, the average degree of the whole network is 6.41 , relatively low. Furthermore, there is a peak value and values on either side of the peak drop rapidly, which is consistent with degree distributing characteristic of the small world network [17].
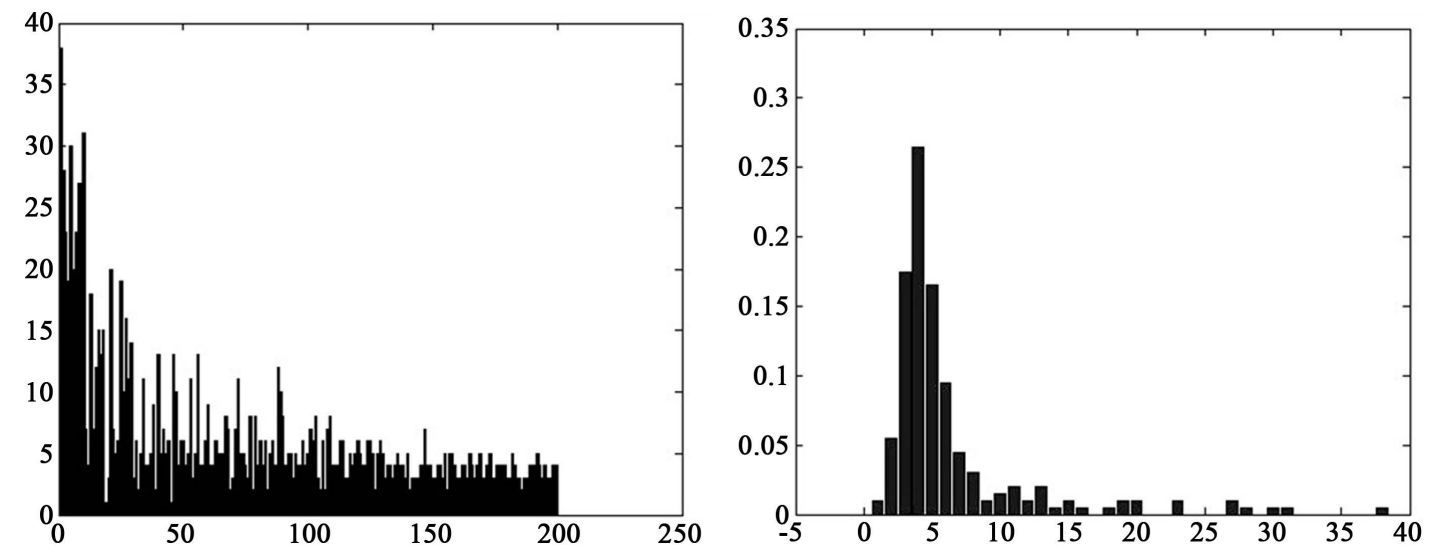

Figure 1. Node degree's distribution and probability of the supply chain complex network. 
By means of the statistical analysis, the established complex network has short average path length and high clustering coefficient that is small-world effect. Secondly, most nodes in the network has low degree and only a few central nodes have high degree, that is power-law distribution of scale-free network [17]. These characteristics are basically consistent with the real supply chain's statistical properties, thus this model can properly describe the supply chain system's topological structure.

\subsection{Divide the Level of Supply Chain Complex Network's Nodes}

Using the cluster analysis to divide the 200 enterprise nodes into three categories, then the supply chain complex network can be divided into three levels: (Tables 1-3).

Setting enterprise nodes whose degrees greater than 23 as the first category (Great probability of risk contagion), degrees greater than 10 and less than 23 as the second category, degrees less than 10 as the third category. Variance analysis showed that the classification is reasonable. The hierarchy dividing of the supply chain complex network according to the classification is as follow: (Table 4).

\subsection{Evaluating Supply Chain’s Credit Risk with Adaptive Weights}

Using Matlab to generate 200 random numbers as the evaluation of enterprises' comprehensive credit state, respectively, 1 random number as the evaluation of financing enterprise's exterior environment. In most cases, better credit state (smaller risk) means greater evaluation of credit state, but there are exceptions, thus method for generating random numbers is as follow (see appendix for detailed numerical):

Randomly generating 170 numbers from 0 to 40, 22 numbers from 30 to 70, 8 numbers from 60 to 100. Then: $\beta_{1}=0.607732, \beta_{2}=0.297903, \beta_{3}=0.094365$. Randomly selecting $S I_{1}=17.63$ in the first layer, then $R_{1}=0.0567$. Randomly selecting $S I_{2}=96.66$ in the third layer, $\phi=87.37$. Following the relevant literature (Liu X. [18]), we assume that $\alpha_{1}=0.478197, \alpha_{2}=0.210172, \alpha_{3}=0.158293, \alpha_{4}=0.153338$. Calculating as Equation (1) can get: $W S=42$, then $R=0.0238$.

However, if the different influences to the system from each layer are not taken into account, which means

Table 1. The final cluster center.

\begin{tabular}{cccc} 
& & Cluster & \\
\cline { 2 - 4 } & 1 & 2 & 3 \\
\hline Node degree & 28.38 & 13.91 & 4.41 \\
\hline
\end{tabular}

Table 2. Analysis of variance.

\begin{tabular}{|c|c|c|c|c|c|c|}
\hline & \multicolumn{2}{|c|}{ Cluster } & \multicolumn{2}{|c|}{ Error } & \multirow{2}{*}{$\mathrm{F}$} & \multirow{2}{*}{ Sig. } \\
\hline & Mean square & Df & Mean square & Df & & \\
\hline Node degree & 2889.846 & 2 & 4.105 & 197 & 703.980 & 0.000 \\
\hline
\end{tabular}

Table 3. The number of cases in each cluster.

\begin{tabular}{ccc}
\hline Cluster 1 & 8.000 \\
2 & 3 & 22.000 \\
Valid & 170.000 \\
Missing & 200.000 \\
\hline
\end{tabular}

Table 4. The hierarchy dividing of the supply chain complex network.

\begin{tabular}{cccc}
\hline Node degree $d_{v_{i}}$ & $d_{v_{i}} \geq 23$ & $23>d_{v_{i}} \geq 10$ & $10>d_{v_{i}} \geq 1$ \\
\hline Hierarchy & The third hierarchy & The second hierarchy & The first hierarchy \\
\hline
\end{tabular}


regarding influences to the whole supply chain from different layers as the same, then $\beta_{1}^{*}=\beta_{2}^{*}=\beta_{3}^{*}=\frac{1}{3}$, Calculating as Equation (1) can get: $W S=45$, then $R=0.0222$.

Result analysis:

1) $R<R_{1}$, it means using controllable credit risk of the whole supply chain, instead of the uncontrollable credit risk of the SME can reduce the credit risk that loaning to SMEs, then solve SME's financing problem;

2) $R>R^{*}$, considering different influences of different enterprise levels can improve credit risk evaluation method's sensitivity, then getting a more accurate measure of the whole supply chain's credit risk.

\section{Conclusions}

Through reasonably fitting the supply chain and bestowing weighing to each layer, this paper considers influences to the supply chain from all enterprises, uses enterprises' status difference to improve the existing evaluation method of supply chain finance credit risk and helps bank to measure loans risk under the background of supply chain more precisely and reduce bank loans' uncertainties, which is beneficial for smoothing the financing channels of SMEs. Through analysis:

1) Supply chain has these characteristics: few core enterprise, choice preference, the contagion of risk, dynamic evolution and complexity regarding the degree of isomerization between the new enterprise and an old one as the standard of establishing $\Psi(t)$, regarding old enterprise's degree as the standard of establishing connection between old and new enterprises. Then, the complex network established has small-world effect, scale-free feature and heterogeneity, so that it can fit the real supply chain well.

2) The probability of spreading risk or being infected of an enterprise is increasing with the amount of business transaction that it has with other enterprises. In other words, enterprises with different status (node degrees) and supply chain layers with different number of enterprise can have differential influences on the chain. So after using clustering methodology to layer the supply chain, the hierarchy with greater range of node degree can get a greater weight, which means its credit risk has a greater effect on the chain's credit risk.

3) Supply chain finance can effectively reduce the risk of SMEs financing and help SMEs solve financial problems.

4) Considering different influences from different enterprise levels can improve the sensitivity of credit risk evaluation method, then getting a more accurate measure of the whole supply chain's credit risk.

\section{References}

[1] Lu, S.Q. (2008) Research on the Generating Mechanism of the Core Enterprise in Supply Chain. Huazhong University of Science and Technology, Wuhan.

[2] Li, X. and Chen, G.R. (2003) A Local-World Evolving Network Model. Physica A, 328, 274-286. http://dx.doi.org/10.1016/S0378-4371(03)00604-6

[3] Xuan, Q., Li, Y.J. and Wu, T.J. (2007) A Local-World Network Model Based on Inter-Node Correlation Degree. Physica A-Statistical Mechanics and its Applications, 378, 561-572. http://dx.doi.org/10.1016/j.physa.2006.11.070

[4] Jensen, H.L. (1992) Using Neural Networks for Credit Scoring. Managerial Finance, 18, 15-26. http://dx.doi.org/10.1108/eb013696

[5] Malhotra, R. and Malhotra, D.K. (2002) Differentiating between Good Credits and Bad Credits Using Neuro-Fuzzy Systems. Computing, Artificial Intelligence and Information Technology, 136, 190-211.

[6] Hallikas, J., Virolainen, V.M. and Tuominen, M. (2002) Risk Analysis and Assessment in Network Environments: A Dyadic Case Study. International Journal of Production Economics, 78, 45-55. http://dx.doi.org/10.1016/S0925-5273(01)00098-6

[7] Azadeh, A. and Alem, S.M. (2010) A Flexible Deterministic, Stochastic, and Fuzzy Data Envelopment Analysis Approach for Supply Chain Risk and Vendor Selection Problem: Simulation Analysis. Expert Systems with Applications, 37, 7438-7448. http://dx.doi.org/10.1016/j.eswa.2010.04.022

[8] Zegordi, S.H. and Davaxzani, H. (2012) Developing a Supply Chain Disruption Analysis Model: Application of Colored Petri-Nets. Expert Systems with Applications, 39, 2102-2111. http://dx.doi.org/10.1016/j.eswa.2011.07.137

[9] Xiong, X., Ma, J., Zhao, W.J. and Zhang, J. (2009) Credit Risk Analysis of Supply Chain Finance. Nankai Business Review, 12, 92-98.

[10] Wang, Q. (2010) The Credit Risk Evaluation of Supply Chain Finance Based on Decision Tree. New Finance, 4, 38- 
41.

[11] Choi, T.Y., Dooley, K.J. and Rungtusanatham, M. (2001) Supply Networks and complex Adaptive Systems: Control versus Emergence t. Journal of Operations Management, 19, 351-366. http://dx.doi.org/10.1016/s0272-6963(00)00068-1

[12] Thadakamalla, H.P., Raghavan, U.N., Kumara, S., et al. (2004) Survivability of Multiagent-Based Supply Networks: A Topological Perspective. IEEE Intelligent Systems, 19, 24-31. http://dx.doi.org/10.1109/MIS.2004.49

[13] Li, G. (2012) Supply Chain Modeling and Performance Analysis Based on Complex Networks. Zhejiang University, Hangzhou.

[14] Gomez-Gardenes, J. and Moreno, Y. (2004) Loeal versus Global Knowledge in the Barabasi-Albert Scale-Free Network Model. Physical Review E, 69, 037-103.

[15] Xia, L.M., Zong, H.H. and Meng, L. (2011) The Construction of Assessment Index System of SME Credit RisksBased on the Perspective of Supply Chain Finance. Finance Forum, 10, 73-79.

[16] Yang, K. and Zhang, Z.Y. (2013) The Research on Mechanism of Supply Chain Network Risk Based on Complex Network Theory. Journal of System Science and Mathematical, 33, 1224-1232.

[17] Albert, R. and Barabási, A.L. (2002) Statistical Mechanics of Complex Network. Review of Modern Physics, 74, 47-97. http://dx.doi.org/10.1103/RevModPhys.74.47

[18] Liu, X. (2012) Supply Chain Finance Model and the Credit Risk Analysis: On the Basis of Financial Institution View. Hubei People’s Press, Wuhan. 


\begin{tabular}{|c|c|c|c|c|c|c|c|c|c|c|c|}
\hline \multicolumn{12}{|c|}{ Randomly generating 8 numbers from 60 to 100} \\
\hline & & 98.07 & 96.66 & 97.87 & 78.94 & 94.55 & 90.14 & 92.37 & 88.44 & & \\
\hline \multicolumn{12}{|c|}{ Randomly generating 22 numbers from 30 to 70} \\
\hline & & 67.21 & 55.77 & 64.37 & 47.15 & 39.36 & 67.53 & 62.65 & 63.14 & & \\
\hline & & 60.32 & 59.08 & 39.32 & 69.39 & 64.86 & 61.96 & 54.31 & 52.49 & & \\
\hline & & 63.78 & 48.52 & 61.11 & 61.64 & 48.12 & 63.02 & & & & \\
\hline \multicolumn{12}{|c|}{ Randomly generating 170 numbers from 0 to 40} \\
\hline 26.40 & 32.26 & 23.21 & 23.68 & 28.51 & 34.08 & 27.48 & 25.15 & 22.59 & 34.87 & 22.71 & 33.80 \\
\hline 38.37 & 38.06 & 37.09 & 15.54 & 18.17 & 31.96 & 23.83 & 26.56 & 26.20 & 35.14 & 11.69 & 34.69 \\
\hline 29.36 & 22.70 & 33.32 & 29.15 & 25.61 & 24.93 & 28.44 & 15.13 & 27.62 & 38.18 & 25.10 & 25.91 \\
\hline 18.06 & 30.18 & 29.09 & 12.78 & 23.80 & 26.70 & 39.15 & 25.62 & 5.07 & 8.39 & 11.83 & 21.16 \\
\hline 29.56 & 31.70 & 31.71 & 20.08 & 28.57 & 26.10 & 25.21 & 21.00 & 33.35 & 36.87 & 7.81 & 30.61 \\
\hline 27.63 & 15.03 & 27.39 & 23.04 & 24.75 & 25.51 & 28.47 & 27.44 & 34.34 & 21.53 & 36.46 & 34.63 \\
\hline 9.43 & 25.80 & 21.87 & 30.52 & 36.07 & 19.76 & 23.92 & 37.34 & 13.80 & 5.87 & 37.23 & 36.09 \\
\hline 23.96 & 28.51 & 23.46 & 22.34 & 30.97 & 29.79 & 19.72 & 30.28 & 36.57 & 13.86 & 39.07 & 28.99 \\
\hline 37.85 & 24.46 & 28.13 & 37.62 & 14.01 & 30.28 & 9.57 & 15.77 & 9.00 & 7.93 & 35.40 & 30.29 \\
\hline 32.61 & 29.07 & 21.48 & 21.64 & 21.13 & 18.65 & 29.21 & 22.72 & 19.06 & 0.60 & 25.85 & 25.18 \\
\hline 15.82 & 29.25 & 7.65 & 27.98 & 11.93 & 30.78 & 26.64 & 31.98 & 30.31 & 26.49 & 30.69 & 29.40 \\
\hline 32.18 & 26.84 & 31.42 & 36.03 & 35.43 & 22.63 & 25.15 & 6.70 & 15.13 & 34.03 & 39.06 & 27.82 \\
\hline 34.05 & 23.04 & 34.88 & 25.96 & 34.79 & 32.41 & 24.54 & 25.89 & 38.81 & 30.88 & 16.43 & 36.58 \\
\hline 31.52 & 34.40 & 26.17 & 24.45 & 38.48 & 17.17 & 32.81 & 19.56 & 29.88 & 34.96 & 32.06 & 15.60 \\
\hline 39.77 & 31.01 & & & & & & & & & & \\
\hline
\end{tabular}

